University of Nebraska - Lincoln

DigitalCommons@University of Nebraska - Lincoln

2000

\title{
Clonal Growth of Lithospermum caroliniense (Boraginaceae) in Contrasting Sand Dune Habitats
}

Stephen G. Weller

University of California - Irvine

Kathleen H. Keeler

University of Nebraska - Lincoln, kkeeler1@unl.edu

Barbara A. Thomson

State University of New York at Stony Brook

Follow this and additional works at: https://digitalcommons.unl.edu/bioscifacpub

Part of the Biodiversity Commons, Botany Commons, Plant Biology Commons, and the Terrestrial and Aquatic Ecology Commons

Weller, Stephen G.; Keeler, Kathleen H.; and Thomson, Barbara A., "Clonal Growth of Lithospermum caroliniense (Boraginaceae) in Contrasting Sand Dune Habitats" (2000). Faculty Publications in the Biological Sciences. 221.

https://digitalcommons.unl.edu/bioscifacpub/221

This Article is brought to you for free and open access by the Papers in the Biological Sciences at DigitalCommons@University of Nebraska - Lincoln. It has been accepted for inclusion in Faculty Publications in the Biological Sciences by an authorized administrator of DigitalCommons@University of Nebraska - Lincoln. 


\title{
Clonal GROWTH OF LITHOSPERMUM CAROLINIENSE (BORAGINACEAE) IN CONTRASTING SAND DUNE HABITATS ${ }^{1}$
}

\author{
Stephen G. Weller, ${ }^{2,5}$ Kathleen H. Keeler, ${ }^{3}$ And \\ BARBARA A. THOMSON ${ }^{4}$

\begin{abstract}
${ }^{2}$ Department of Ecology and Evolutionary Biology, University of California, Irvine, California 92697-2525 USA;
${ }^{3}$ School of Biological Sciences, University of Nebraska, Lincoln, Nebraska 68588-0343 USA; and

${ }^{4}$ Department of Ecology and Evolution, State University of New York at Stony Brook, Stony Brook, New York 11794-5245 USA
\end{abstract}

\begin{abstract}
The occurrence of clonal growth of distylous Lithospermum caroliniense was investigated in a population in the Nebraska Sandhills, an area where sand dunes have been relatively stable for at least 1500-3000 yr, and compared to a population occurring at the Indiana Dunes, an area of active sand dune formation. Spatial autocorrelation analysis indicated the occurrence of significant clonal propagation of genetically based floral morphs at Arapaho Prairie, but not for the Indiana Dunes. Apparent clonal growth in the Sandhills population had no overall negative effect on pollen deposition or fecundity relative to the Indiana population, although in some large clones the proportion of compatible pollen grains on stigmas was lower. Clonal growth may have occurred in the Sandhills population because of the greater age and stability of the Nebraska Sandhills; infrequent establishment of seedlings permits detection of clonal growth using the spatial pattern of floral morphs. At the Indiana dunes, repeated cycles of dune formation provide conditions favoring establishment of seedlings, and sand dune succession results in disappearance of $L$. caroliniense before the development of clones.
\end{abstract}

Key words: Boraginaceae; emergence; establishment; fecundity; heterostyly; Lithospermum caroliniense; pollen flow; spatial autocorrelation; self-incompatibility.

Clonal growth can influence spatial patterns of morphs or mating types within sexually dimorphic or self-incompatible species (Levin, 1974; Ornduff and Weller, 1975; Wyatt and Hellwig, 1979; Barrett and Thomson, 1982; Sakai and Burris, 1985; Aspinwall and Christian, 1992; Husband and Barrett, 1992). During reproduction, such pattern is unlikely to be adaptive, because transfer of pollen from one self-incompatibility morph to another, or from staminate to pistillate plants in the case of dioecious species, will probably be impeded by the presence of large clones. Even moderate establishment from seed within a clone, however, would prevent the development of spatial pattern as seedlings of the opposite sex, floral morph, or mating type reached reproductive age. In this paper we investigate the occurrence of spatial pattern of reproductive morphs in populations of Lithospermum caroliniense, the effects of clone size on pollen deposition and fecundity, and potential causes for clonal growth.

Lithospermum caroliniense (Walt.) MacM. (Boraginaceae) is a herbaceous perennial occurring on sand dunes in the eastern United States. Lithospermum caroliniense has a heterostylous breeding system: plants produce ei-

\footnotetext{
${ }^{1}$ Manuscript received 6 November 1998; revision accepted 15 June 1999.

The authors thank the director and staff of the Cedar Point Biological Station, University of Nebraska, for the use of their facility, The Nature Conservancy for permission to carry out research at Arapaho Prairie, Christine Guth for help in mapping the Indiana Dunes population, and Bill Platt, Ann Sakai, and James Thomson for manuscript review. Grants to SGW from the National Science Foundation (DEB 8021160) and the Andrew W. Mellon Foundation, through the Smithsonian Institution, supported this research.

5 Author for correspondence.
}

ther short-styled (thrum) flowers or long-styled (pin) flowers. As expected for most heterostylous species, $L$. caroliniense is strongly self-incompatible throughout its range, and only pollen movement occurring between pin and thrum plants yields fruits (Kerster and Levin, 1968; Weller, unpublished data).

Establishment of $L$. caroliniense from seeds (technically nutlets) is favored by abundant and even rainfall, large nutlet mass, and burial of nutlets at an intermediate depth (Weller, 1985b). Limited dispersal of nutlets of $L$. caroliniense eventually results in significant aggregation of seedlings, juveniles, and adults. We quantified the extent of potential clonal growth at the Indiana Dunes and a population of $L$. caroliniense at Arapaho Prairie in Nebraska, where preliminary observations suggested that establishment from seed was uncommon. We also investigated the effects of such pattern on pollen deposition and nutlet production. We interpreted the features of the population biology of $L$. caroliniense at Indiana Dunes vs. the Sandhills that might contribute to differential clonal growth in the two regions.

\section{MATERIALS AND METHODS}

Study populations, identification of clones, and spatial autocorrelation techniques - The Indiana dunes population of L. caroliniense occurred at Miller Dunes, the westernmost part of the Indiana Dunes National Lakeshore. In this area, the dunes are very active, with repeated cycles of dune accretion and erosion that are correlated with changes in the level of Lake Michigan (Olson, 1958a, b). Olson (1958a) estimated that $\sim 90$ dune ridges roughly parallel to the Lake Michigan shoreline formed over a period of $2700 \mathrm{yr}$, indicating that major dune ridges have formed approximately every $30 \mathrm{yr}$. Plants occurring in a 12 $\times 16 \mathrm{~m}$ site bordering an interdunal pond (Pond Margin; described in 
Weller [1985a]) were mapped to the nearest centimetre in 1984. Based on Olson's estimates for the age of the major dune crests, the area where L. caroliniense was mapped is at least $90 \mathrm{yr}$ in age, and probably older. The mapped area represented the extent of a local population of $L$. caroliniense and contained 55 spatially distinct flowering individuals. Many other local populations occurred nearby.

At Arapaho Prairie, a reserve of Sandhill prairie owned by The Nature Conservancy and managed by the School of Biological Sciences, University of Nebraska, the more gently rolling topography and stable sand surface contrast sharply with the Indiana Dunes. Arapaho Prairie has not been grazed or burned since 1976 (Keeler, Harrison, and Vescio, 1980); changes resulting from cessation of fire and grazing are described in Jones and Ballinger (1985). In 1991, a total of 337 spatially distinct flowering individuals were mapped in a $100 \times 70 \mathrm{~m}$ area on a westfacing hillside. This area represents a small portion of a very large population of $L$. caroliniense.

Individuals were defined as having one or more contiguous stems (ramets) emerging in a tight cluster from the sand and possessing the same style morph; these individuals probably represent genets. Noncontiguous stems ( $>3 \mathrm{~cm}$ apart) were considered to represent different individuals and may or may not have been part of the same genet. Patches of individuals possessing the same style morph were assumed to have arisen from clonal growth. A putative clone could contain varying numbers of individuals each with one to several stems. No attempts were made to excavate plants to determine whether putative clone members were attached because of the brittle nature of the root system and the occurrence of these plants in ecological reserves.

The spatial autocorrelation of style morphs was used as an indication of putative clonal growth (Cliff and Ord, 1981; Sokal and Oden, 1978a, b; Sokal and Thomson 1987). Spatial autocorrelation was measured using AUTOCOR, a program written by Neal L. Oden for nominal data, in this case using pin and thrum morphs as the nominal classes. We tested the null hypothesis that pin and thrum individuals are randomly distributed with respect to one another. Significant spatial autocorrelation occurs if pin individuals are more likely to occur near pin individuals and thrum individuals are more likely to occur near thrum individuals. This pattern would be expected if clonal growth had occurred, although a significant finding does not rule out other explanations. The upper limits of the 20 distance classes for both sites were $0.25,0.5,0.75, \ldots, 5 \mathrm{~m}$, with an additional analysis using upper limits of $0.5,1,1.5, \ldots, 10 \mathrm{~m}$ for the Nebraska site. Significance of spatial autocorrelation was tested using a two-tailed test. Standardized values for numbers of matches (observed-expected/standard deviation) were plotted. Values $>1.96$ or $<-1.96$ were considered significant at $P<0.05$.

Clonal extent, pollen deposition, nutlet production, and seedling emergence - To determine the effects of potential clonal growth on pollen deposition at Arapaho Prairie, stigmas were collected on 28 June 1991, from $\sim 25$ pin and 25 thrum ramets. Sampling was stratifiedhaphazard: an attempt was made to collect stigmas from one individual per putative clone. Stigmas were collected from young (two most recently opened flowers on a cyme, designated P12 or T12) vs. old stigmas (third and fourth oldest flowers on a cyme when possible, designated P34 or T34; in many cases, the oldest flower had withered). Using previously described techniques (Weller, 1980), stigmas were acetolyzed, and the average number of pollen grains per stigma of each morph was calculated. Pollen grains of floral morphs of $L$. caroliniense are very strongly dimorphic in size and shape, which permits ready classification of the source of pollen on stigmas. To contrast observed pollen loads on stigmas with those expected if pollen deposition occurred in proportion to pollen production (Ganders, 1974), average pollen production for ten pin and ten thrum individuals was calculated by removing pollen of undehisced anthers from one flower per individual. Pollen from these anthers was suspended in lactophenol, and known volumes were removed for counting using hemacytometers (Weller,

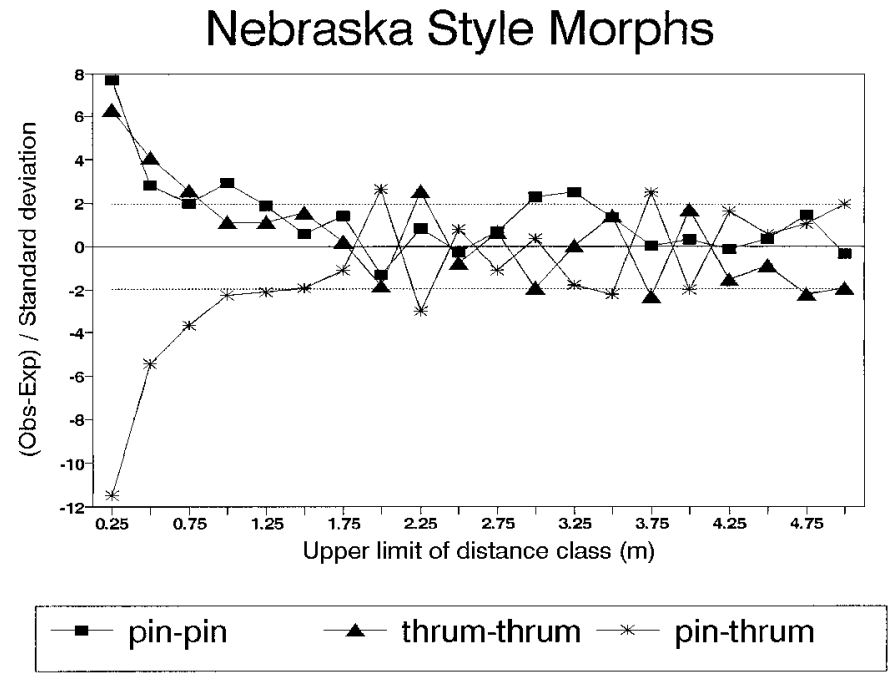

Fig. 1. Spatial autocorrelation of style morphs of L. caroliniense at Arapaho Prairie, Nebraska, using 20 equal-interval distance classes up to $5 \mathrm{~m}$. Matches of style morph per distance class for three style morph combinations: pin-pin, thrum-thrum, and pin-thrum. The abscissa represents distance in metres (upper limits of distance classes). The ordinate represents number of matches in standard deviation units. Values outside the dotted lines (at 1.96 and -1.96 ) are significant at $P<0.05$.

1980). Total pollen availability was corrected for style morph representation by counting the total number of pin and thrum ramets in the plot.

The effect of large clone size on pollen deposition was investigated by collecting all available stigmas in four large, isolated clones (typical clone size was $<0.4 \mathrm{~m}^{2}$; isolated, large clones averaged $1.8 \mathrm{~m}^{2}$ ). Only young stigmas were collected in isolated clones as not enough older stigmas were available for analysis. Although flowers were not emasculated, which precludes distinguishing among self, geitonogamous, or intramorph outcross pollen, differences in the proportion of intermorph pollen were detectable because of the striking pollen dimorphism. For these putative clones, the number of flowering ramets, area covered by the clone, and distance to the nearest clone of the opposite style morph were recorded. Differences in pollen loads for clones were compared to overall pollen loads in the population using $G$ tests.

Nutlet production and seedling emergence at Arapaho Prairie were noted in 1991-1993. Areas with mapped plants were searched thoroughly for presence of seedlings of $L$. caroliniense, which are conspicuous, emerge synchronously in the early spring, and easily detected even after death. Information on pollen loads, nutlet production, and seedling emergence reported earlier for 1978-1982 at the Indiana Dunes (Weller, 1985a) was used for comparison to data collected in Nebraska. Two-way ANOVA was used for comparison of nutlet production at the two sites (SAS, 1990). Because flowers produce a maximum of four nutlets, fecundity was scored as a percentage, and arcsine transformations were used before data analyses.

\section{RESULTS}

Lithospermum caroliniense style morphs showed highly significant spatial autocorrelation at the Arapaho Prairie population, a pattern consistent with clonal propagation. In the Nebraska population, significant positive autocorrelation of style morphs occurred at distances of up to $1 \mathrm{~m}$ for pins and $75 \mathrm{~cm}$ for thrums $(P<0.05$ in both cases, 25-cm intervals; Fig. 1), with the most significant positive spatial autocorrelation $(P<0.001)$ occurring at $25 \mathrm{~cm}$. Significant values for spatial autocorrelation $(0.01$ $<P<0.05)$ occurred occasionally at greater distances, 


\section{Indiana Dunes Style Morphs}

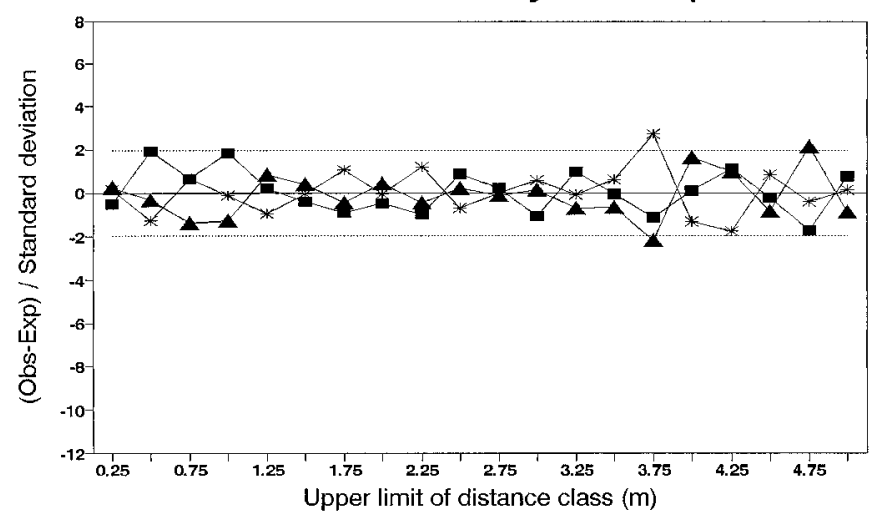

\section{$\rightarrow$ pin-pin $\quad \leftarrow$ thrum-thrum $\rightarrow$ pin-thrum}

Fig. 2. Spatial autocorrelation of style morphs of $L$. caroliniense at the Indiana Dunes, Lake County, Indiana, using 20 equal-interval distance classes up to $5 \mathrm{~m}$.

but no strong pattern could be detected, and the $P$ values at greater distances were far lower than those obtained at the shorter distances.

At the Indiana Dunes no spatial autocorrelation could be detected among adjacent plants (Fig. 2). Using upper limits of distance classes every $25 \mathrm{~cm}$ for $5 \mathrm{~m}$, a significant value for spatial autocorrelation was obtained at a distance of $3.75 \mathrm{~m}$. No consistent pattern comparable to the results found in the Arapaho population could be detected. Although the Indiana population was mapped at a different time than the Nebraska population, comparison of the two populations is facilitated by the slow recruitment of adult individuals into the Indiana population (Weller, 1985a). Spatial pattern did not change appreciably over the 10-yr period of observation of this population (Weller, unpublished observations).

At Arapaho Prairie, anthers of pin flowers produced almost twice as much pollen per flower $(72820 \pm 12821$ [SD] grains) as those of thrum flowers $(38280 \pm 4873$ [SD] grains). With corrections for the number of pin ( $N$
$=349)$ and thrum $(N=458)$ ramets in the population, $59.2 \%$ of the pollen available to pollinators was produced by pin plants and $40.8 \%$ was produced by thrum flowers.

The majority $(96.4 \%)$ of pollen on young pin stigmas collected throughout the population (P12 sample) was produced by pins, either from anthers in the same flower (self-pollination), pollen produced by other pin flowers on the same plant (geitonogamous pollination), or pollen produced by other pin plants in the population (own-form pollination; Table 1). The number of pin pollen grains increased on older pin stigmas (P34 sample; Table 1), although the number of thrum pollen grains stayed at the same approximate level. The percentage of compatible (thrum) pollen declined from 3.6 to $2.4 \%$ as flowers aged.

Far fewer pollen grains were found on thrum stigmas. On younger stigmas (T12 sample), averages of 21.6 pin pollen grains and 26.7 thrum pollen grains were found (Table 1), leading to a higher proportion of compatible pollination $(44.7 \%)$ compared to pin stigmas. The total number of pollen grains increased by a factor of $\sim 4$ in the older (T34) sample (Table 1), with a very slight increase in the proportion of compatible pollen to $48.8 \%$.

Analysis of pollen loads on stigmas from the large, isolated clones yielded no consistent patterns in the proportion of compatible pollen grains on stigmas (Table 1). For pin clone 1, there was an average of only $3.7(0.48 \%)$ thrum pollen grains on the stigmas, a value that was significantly lower than the overall population sample $(G=$ 22.3 , df $=1)$. For pin clone 2 there was an average of $29.6(4.23 \%)$ thrum grains per stigma, similar to the overall population sample $(G=0.408)$. The nearest thrum plants were $0.8 \mathrm{~m}$ for the first clone and $1.3 \mathrm{~m}$ for the second clone.

The first of the thrum clones averaged 44.4 (16.2\%) pin pollen grains per stigma, a far smaller proportion than in the overall population sample $(G=18.1, \mathrm{df}=1)$. The nearest pin plants were $0.5 \mathrm{~m}$ from the edge of the clone. The second thrum clone, isolated by $2.4 \mathrm{~m}$ from the nearest pin plants, averaged 63.0 pin pollen grains per stigma $(30.9 \%)$, a value similar to the overall population $(G=$ 3.37).

Fecundity, estimated as the number of nutlets formed out of the maximum of four possible per flower, was low

TABle 1. Pollen loads on stigmas of Lithospermum caroliniense at Arapaho Prairie. Compatible-load loads are also expressed in parentheses. Sample size $(N)$ refers to the number of pin or thrum flowers in each category.

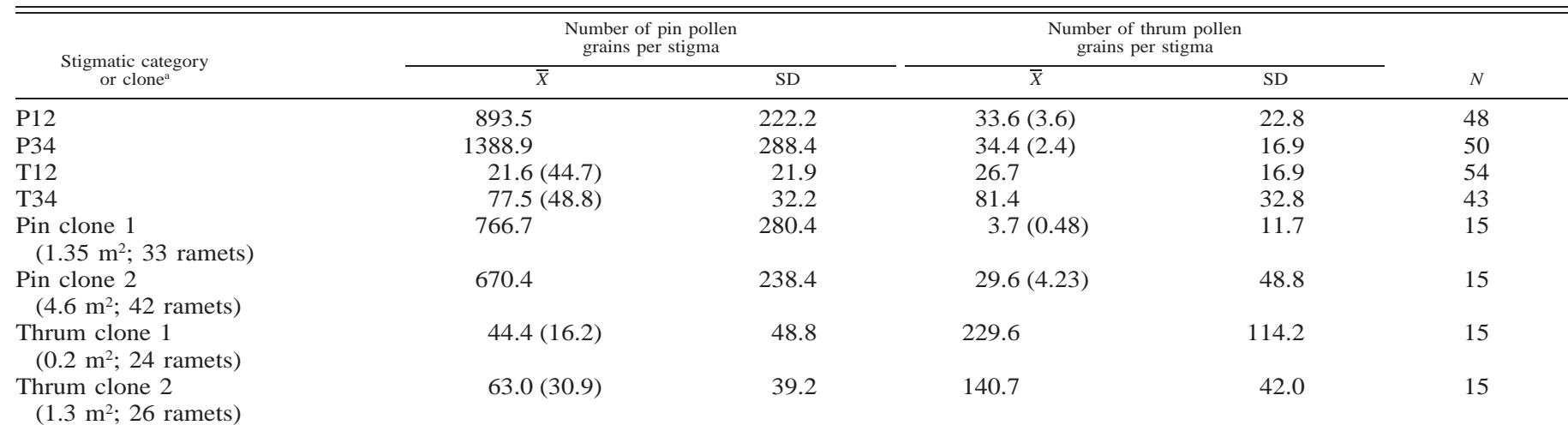

${ }^{a} \mathrm{P}=$ pin (long-style); $\mathrm{T}=$ thrum (short-style); numbers after $\mathrm{P}$ or $\mathrm{T}$ indicate age of the flower; 1 is youngest flower on the helicoid cyme. Areal extent of clones and number of ramets are noted. 
for both sites, although overall nutlet production was greater at Arapaho Prairie $(F=18.88$, df $=1,124 ; P<$ $0.0001)$. At Arapaho Prairie, nutlet production for individuals averaged $14.2 \%(N=59)$, less than one nutlet per flower. Fecundity averaged $15.4 \%$ for thrums $(N=$ $25) ; 13.8 \%$ for pins $(N=24)$; and $12.0 \%$ for plants of unknown style morph $(N=10)$. At the Indiana Dunes, based on data collected from a 5-yr period (1978-1982; Weller, 1985a), overall fecundity of plants was $10.1 \%$. Nutlet production for site and floral morph interacted significantly $(F=6.98$, df $=1,124 ; P=0.0093)$ as a result of the greater nutlet production of pins at the Indiana Dunes $(12.3 \%$ for pins $[N=29] ; 8.52 \%$ for thrums $[N$ $=41]$ ).

Seedling emergence was very low in all $3 \mathrm{yr}$ at Arapaho Prairie (18 seedlings in 1991, two in 1992, and eight in 1993, yielding an average density of 0.0013 seedlings/ $\mathrm{m}^{2}$ for the area mapped). In contrast, at the Indiana site a $192-\mathrm{m}^{2}$ area had an average seedling density over $4 \mathrm{yr}$ of 115 ( $\mathrm{SD}=39.4)$, or 0.60 seedlings $/ \mathrm{m}^{2}$, a 450 -fold difference in seedling density compared to the Sandhills site.

\section{DISCUSSION}

Differences in the degree of spatial autocorrelation suggest that populations of $L$. caroliniense vary in detectable levels of clonal growth at the Arapaho Prairie and the Indiana Dunes National Lakeshore. No spatial autocorrelation of style morphs could be detected at the Indiana Dunes, while at Arapaho Prairie apparent clones of sizes up to $1 \mathrm{~m}$ could be detected. It seems unlikely that putative clones were much larger than $1 \mathrm{~m}$ because patches containing the same style morph were generally isolated from other Lithospermum plants.

Even rare establishment from seed should prevent the development of spatial pattern in populations of $L$. caroliniense over distances of 1-2 $\mathrm{m}$ because pin and thrum morphs segregate equally in the progeny of both style morphs of this species. Even with clonal growth, seedling establishment should soon lead to the presence of two style morphs in close proximity, unless severe post-establishment competition resulted in survival of a single clone in one area. At the Indiana Dunes numerous seedlings emerged each spring, and many survived in years of evenly distributed rainfall and moderate temperatures (Weller, 1985a). The presence of patches of single-style morphs at Arapaho Prairie suggests that sexual reproduction is rare, perhaps because of limited compatible pollination, low fecundity, or the failure of nutlets to germinate following dispersal. Each of these possibilities is discussed in turn.

Pollen loads on stigmas of L. caroliniense at Arapaho Prairie were similar to those found at the Indiana Dunes in a year of high levels of compatible pollen deposition. In general, it appears that compatible pollen loads were high enough at Arapaho Prairie to prevent a reduction in fecundity, based on a multiyear comparison of pollen loads and fecundity at the Indiana Dunes (Weller, 1980, 1985a), which indicate that 30-40 compatible pollen grains on a stigma result in maximal nutlet production. For comparison, compatible pollen loads at Arapaho Prairie ranged from an average of 34.4 to 77.5 pollen grains on older stigmas.
Large clone size and distance to the nearest compatible plant had no obvious effect on deposition of compatible pollen. In two of the four large clones that were examined, there were statistically significant reductions in the proportion of compatible pollen grains on stigmas relative to the population as a whole (Table 1). Lower legitimate pollen loads in large clones may result from the tendency for pollinators to forage over short distances. In $1987,51 \%$ of all bumble bees, which appear to be important pollinators of $L$. caroliniense, flew less than $1 \mathrm{~m}$ between flowers (Weller and Keeler, personal observation). In a large clone, this could lead to higher levels of geitonogamous pollination than in smaller clones, where insect flights from other clones are more likely. Detailed observations of pollinator flights would be necessary to better understand the potential effects of clonal growth on pollination and fruit production.

When the interaction of clone size and self-incompatibility or dioecy has been investigated for other species, results have been mixed. Large clone size in combination with strong self-incompatibility was found to impede fruit production in distylous, self-incompatible Houstonia caerulea (Wyatt and Hellwig, 1979), although no such pattern could be detected in the clonal, self-incompatible species Filipendula rubra (Aspinwall and Christian, 1992). In an investigation of spatial pattern of pistillate and staminate ramets of clonal Aralia nudicaulis (Araliaceae), proximity of males had little effect on fecundity of females (Barrett and Thomson, 1982). They concluded that resource limitation was more likely to affect fruit production than insufficient pollination resulting from spatial pattern, except perhaps at the centers of the largest clones.

It is unlikely that differences in fecundity or pollen loads explain the small number of seedlings at Arapaho Prairie relative to the Indiana Dunes. Although fecundity of L. caroliniense at Arapaho Prairie was significantly greater than fecundity at the Indiana Dunes, on average less than one ovule per flower developed into a nutlet at either site. Similar low levels of nutlet production are characteristic of other species of Boraginaceae (Weller and Ornduff, 1977; Casper and Wiens, 1981). It seems clear that except in years of extremely low levels of pollination (Indiana Dunes, 1978; Weller, 1985a), or perhaps in large clones, fecundity is unaffected by level of compatible pollination, which typically varies much more than fecundity (Weller, 1980, 1985a).

Differences in seedling establishment are the most likely explanation for the development of spatial pattern in the Arapaho population. Seedlings were observed only rarely over 3 yr of observation in this population and far less frequently than over the 10 -yr period of observation at the Indiana Dunes. The differences are likely to be characteristic of the populations, given that the very large disparity in recruitment was consistent across years. Low emergence at Arapaho Prairie may result from relatively stable sand surfaces and the failure of most nutlets to be buried at depths with levels of moisture favoring germination (Weller, 1985b, 1989). Exposure of nutlets on the sand surface also may increase the number eaten by rodents, especially in years of low snow cover (Weller, 1985a). For some species, competition may result in reduced establishment from seed within the boundaries of 
a clone (Waller, 1988; Aspinwall and Christian, 1992), or in reductions in genetic diversity associated with increasing clone density (Harper, 1977).

Differences in the development and history of the Arapaho and Indiana Dunes may explain the contrast in levels of clonal growth and recruitment at the two sites. The Nebraska Sandhills were formed from wind-blown sediments released from receding glaciers at the end of the Pleistocene Era. Following a major episode of sand dune formation 8000-5000 yr ago during a warm, dry period (Swinehart and Diffendal, 1990), the Sandhills have probably undergone several periods of more recent activity, including late Holocene dune formation 30001500 yr before present (Ahlbrandt, Swinehart, and Maroney, 1983). Blowouts form at the crest of the higher dunes, where moisture is limiting and plant cover may be insufficient to prevent sand movement, but overall, the Sandhills are relatively stable at present (Ahlbrandt, Swinehart, and Maroney, 1983). Lithospermum caroliniense occurs on the more prevalent, vegetated portions of the dunes rather than in blowouts.

Dunes along the south shore of Lake Michigan have formed sequentially as Lake Michigan receded following Pleistocene glaciation and are much younger than the Sandhills, suggesting that in the area where plants were mapped there may not have been time for the development of clones. During the course of $10 \mathrm{yr}$ of observation of marked plants in this area, all establishment was from seed (Weller, unpublished observations). Considerable time is probably required before clonal spread of $L$. caroliniense is evident. At the Indiana Dunes, increased mortality due to successional changes on the older dunes may in general prevent development of spatial pattern, even though plants presumably have the capacity for clonal propagation (Weller, 1985a).

In a study of L. caroliniense (called L. croceum in her study) on stabilized dunes that developed around Pleistocene Lake Michigan, McCall (1996) also detected development of clones. Presumably the greater age of this population and the failure of establishment from seeds permit recognition of clonal growth based on distribution of style morphs (C. McCall, personal communication, 1996), as in the case of L. caroliniense at Arapaho Prairie. The occurrence of the extensive clones characteristic of Aralia nudicaulis (Barrett and Thomson, 1982) and Populus tremuloides (Sakai and Burris, 1985) may result from both sufficient time for development of clones following establishment from seed and subsequent suppression of further seedling establishment that would interfere with detection of clonal growth using spatial pattern in sex morphs.

The population of $L$. caroliniense at Arapaho Prairie may be a relict established under very different conditions than those that occur at present. Although sand dune succession on dunes bordering Lake Michigan has long been a major paradigm in successional studies, the population biology of $L$. caroliniense at Arapaho Prairie, an area far removed from the prairie-forest ecotone, suggests conditions that are stable. These conditions provide little opportunity for repeated bouts of seedling establishment via seed characteristic of populations of $L$. caroliniense bordering the Great Lakes. At Arapaho Prairie, relative ecological stability may have shifted emphasis from re- cruitment via seed to persistence of adults of $L$. caroliniense. The extent to which shifts in ecological conditions may lead to evolutionary modifications of life history characteristics (e.g., Werner and Platt, 1976) is unknown and would depend in part on the frequency of establishment from seed.

\section{LITERATURE CITED}

Ahlbrandt, T. S., J. B. Swinehart, and D. G. Maroney. 1983. The dynamic Holocene dune fields of the great plains and Rocky Mountain basins, U.S.A. In M. E. Brookfield and T. S. Ahlbrandt [eds.], Eolian sediments and processes, 379-406. Elsevier, Amsterdam, The Netherlands.

Aspinwall, N., AND T. Christian. 1992. Clonal structure, genotypic diversity, and seed production in populations of Filipendula rubra (Rosaceae) from the northcentral United States. American Journal of Botany 79: 294-299.

Barrett, S. C. H., AND J. D. Thomson. 1982. Spatial pattern, floral sex ratios, and fecundity in dioecious Aralia nudicaulis (Araliaceae). Canadian Journal of Botany 60: 1662-1670.

CAsper, B. B., AND D. WiEns. 1981. Fixed rates of random ovule abortion in Cryptantha flava (Boraginaceae) and its possible relation to seed dispersal. Ecology 62: 866-869.

Cliff, A. D., AND J. K. ORD. 1981. Spatial processes. Pion, London, UK.

GANDERS, F. R. 1974. Disassortative pollination in the distylous plant Jepsonia heterandra. Canadian Journal of Botany 52: 2401-2406.

Harper, J. L. 1977. Population biology of plants. Academic Press, London, UK.

Husband, B. C., And S. C. H. Barrett. 1992. Pollinator visitation in populations of tristylous Eichhornia paniculata in northeastern Brazil. Oecologia 89: 365-371.

Jones, S. M., AND R. E. BALlinger. 1985. Ecological disturbance in a sandhills prairie: impact and importance to the lizard community on Arapaho Prairie. Prairie Naturalist 17: 91-100.

Keeler, K. H., A. T. Harrison, And L. S. Vescio. 1980. The flora and sandhills prairie communities of Arapaho Prairie, Arthur County, Nebraska. Prairie Naturalist 12: 65-78.

Kerster, H. W., AND D. A. LeVIN. 1968. Neighborhood size in Lithospermum caroliniense. Genetics 60: 577-587.

LEVIN, D. A. 1974. Spatial segregation of pins and thrums in populations of Hedyotis nigricans. Evolution 28: 648-655.

MCCALL, C. 1996. Gender specialization and distyly in hoary puccoon, Lithospermum croceum (Boraginaceae). American Journal of Botany 83: $162-168$.

Olson, J. S. 1958a. Lake Michigan dune development. 2. Plants as agents and tools in geomorphology. Journal of Geology 66: 345351.

. 1958b. Lake Michigan dune development. 3. Lake-level, beach, and dune oscillations. Journal of Geology 66: 473-483

Ornduff, R., And S. G. Weller. 1975. Pattern diversity of incompatibility groups in Jepsonia heterandra (Saxifragaceae). Evolution 29: 373-375.

SAKAI, A. K., AND T. BurRIS. 1985. Growth in male and female aspen clones: a twenty-five-year longitudinal study. Ecology 66: 19211927.

SAS. 1990. SAS/STAT user's guide, version 6, ed. 4, vol. 2. SAS Institute, Cary, North Carolina, USA.

SOKAL, R. R., AND N. L. ODEN. 1978a. Spatial autocorrelation in biology 1: methodology. Biological Journal of the Linnean Society 10: 199-228.

, AND - 1978b. Spatial autocorrelation in biology 2 Some biological implications and four applications of evolutionary and ecological interest. Biological Journal of the Linnean Society 10: 229-249.

, AND J. D. Thomson. 1987. Applications of spatial autocorrelation in ecology. In P. Legendre and L. Legendre, [eds], Developments in numerical ecology, 431-466. NATO Advanced Study Institute Series G (Ecological Sciences). Springer-Verlag, Berlin, Germany.

Swinehart, J. B., AND R. F. Diffendal, JR. 1990. Geology of the pre- 
dune strata. In A. Bleed and C. Flowerday [eds.], An atlas of the Sand Hills, 29-56. Conservation and Survey Division, University of Nebraska, Lincoln, Nebraska, USA.

WALLER, D. M. 1988. Plant morphology and reproduction. In J. Lovett Doust and L. Lovett Doust, [eds], Plant reproductive ecology: patterns and strategies, 203-227. Oxford University Press, Oxford, UK.

Weller, S. G. 1980. Pollen flow and fecundity in populations of Lithospermum caroliniense. American Journal of Botany 67: 13341341.

1985a. The life history of Lithospermum caroliniense, a longlived herbaceous sand dune species. Ecological Monographs 55: 49-67. 1985b. Establishment of Lithospermum caroliniense on sand dunes: the role of nutlet mass. Ecology 66: 1893-1901.

1989. The effect of disturbance scale on sand dune colonization by Lithospermum caroliniense. Ecology 70: 1244-1251.

-, AND R. ORNDUFF. 1977. Cryptic self-incompatibility in Amsinckia grandiflora. Evolution 31: 47-51.

Werner, P. A., AND W. J. Platt. 1976. Ecological relationships of cooccurring goldenrods (Solidago: Compositae). American Naturalist 110: 959-971.

Wyatt, R., and R. L. Hellwig. 1979. Factors determining fruit set in heterostylous bluets, Houstonia caerulea (Rubiaceae). Systematic Botany 4: 103-114. 